\title{
AS HISTÓRIAS DE VIDA DE PROFESSORAS INICIANTES NO PROCESSO DE CONSTITUIÇÃO DA DOCÊNCIA
}

\author{
Joelson de Sousa Morais (UNICAMP)* \\ https://orcid.org/0000-0003-1893-1316 \\ Inês Ferreira de Souza Bragança (FE/UNICAMP)** \\ https://orcid.org/0000-0003-4782-1167
}

\section{RESUMO}

Este artigo partilha uma pesquisa qualitativa que prima pela abordagem teórico-metodológica das histórias de vida, especialmente por meio do diário de pesquisa e das narrativas orais, realizados com três professoras iniciantes, que atuam nos anos iniciais do Ensino Fundamental numa escola pública de Caxias (MA). Os objetivos buscam: compreender as implicações das histórias de vida na constituição da docência de professoras em início de carreira, bem como refletir acerca das potencialidades das histórias de vida no desenvolvimento profissional de professoras iniciantes. 0 artigo respalda-se em autores do campo das histórias de vida e narrativas (auto)biográficas em educação. Os resultados evidenciam que as histórias de vida das professoras iniciantes trazem inúmeras implicações profissionais por terem escolhido a docência como vida e profissão, as quais obtiveram contributos pelas suas experiências vivenciadas no passado em fazeres relacionadas à educação, bem como influência da família e das próprias escolhas pessoais para exercer a profissão docente.

Palavras-chave: Histórias de vida. Pesquisa-formação. Professoras iniciantes.

\section{KEYWORDS}

\section{LIFE STORIES OF INITIATING TEACHER IN THE TEACHER CONSTITUTION PROCESS}

This article is a qualitative research that strives for the methodological resource of life histories, research diary and observations, conducted with three beginning

\footnotetext{
Doutorando em Educação pela Universidade Estadual de Campinas (UNICAMP). Pesquisador do Grupo de Estudos e Pesquisas em Educação Continuada (GEPEC/UNICAMP), do Grupo Interinstitucional de Pesquisa-Formação Polifonia (UNICAMP/UERJ) e do Grupo de Pesquisas Interdisciplinares: Educação, Saúde e Sociedade da Universidade Estadual do Maranhão (UEMA/ CNPQ).E-mail: joelsonmorais@hotmail.com

** Pós-Doutorado pelo programa de Pós-Graduação em Educação da Pontifícia Universidade Católica do Rio Grande do Sul (PUC/RS) e Doutora em Ciências da Educação pela Universidade de Évora-Portugal. Professora Doutora da Faculdade de Educação da Universidade Estadual de Campinas (FE/UNICAMP) e professora colaboradora do Programa de Pós-Graduação Processos Formativos e Desigualdades Sociais da Faculdade de Formação de Professores da Universidade Estadual do Rio de Janeiro (FFP/UERJ). Pesquisadora do Grupo de Estudos e Pesquisas em Educação Continuada (GEPEC/UNICAMP), do Núcleo de Pesquisa e Extensão Vozes da Educação (FFP/UERJ) e coordenadora do Grupo Interinstitucional de Pesquisa-Formação Polifonia (UNICAMP/UERJ). E-mail: inesbraganca@uol.com.br
} 
teachers who work in the early years of elementary school in a public school in Caxias (MA). The objectives seek: to understand the impleications of life histories in the constitution of teachers of early career teachers, as well as to reflect on the potentialities of life stories in the professional development of beginning teachers. The article is supported by authors from the field of life stories and (self) biographical narratives in education. The results show that the life histories of the beginner teachers surveyed have numerous professional implications for choosing teaching as life and profession, which obtained contributions for their past experiences in activities related to education, as well as the influence of family and their own. personal choices to exercise the teaching profession.

Keywords: Life stories. Training research. Beginner teachers.

\section{RESUMEN}

\section{HISTORIAS DE VIDA DE INICIAR AL PROFESOR EN EL PROCESO DE CONSTITUCIÓN DEL PROFESOR}

Este artículo es una investigación cualitativa que se esfuerza por el recurso metodológico de historias de vida, diario de investigación y observaciones, realizado con tres maestros principiantes que trabajan en los primeros años de la escuela primaria en una escuela pública en Caxias (MA). Los objetivos buscan: comprender las implicaciones de las historias de vida en la constitución de maestros de maestros de carrera temprana, así como reflexionar sobre las potencialidades de las historias de vida en el desarrollo profesional de los maestros principiantes. El artículo está respaldado por autores del campo de historias de vida y narraciones (auto) biográficas en educación. Los resultados muestran que las historias de vida de los maestros principiantes encuestados tienen numerosas implicaciones profesionales para elegir la enseñanza como vida y profesión, que obtuvieron contribuciones por sus experiencias pasadas en actividades relacionadas con la educación, así como la influencia de la familia y la suya. opciones personales para ejercer la profesión docente.

Palabras clave: Historias de vida. Investigación de formación. Maestros principiantes.

\section{Notas Introdutórias}

A sociedade vem, ao longo do tempo, passando por profundas e vertiginosas mudanças em várias esferas, escalas e dimensões, alterando, consequentemente, as relações humanas, os modos de pensar, fazer e produzir as profissões, as metamorfoses no conhecimento, na existência e na vida dos sujeitos, trazendo, inclusive, implicações na cultura, na educação e, assim, na formação e na profissionalização docente.

Em relação à profissão docente, se defronta com uma infinidade de saberes, fazeres e conhecimentos que são elaborados e (re)elaborados em razão da conjuntura histórico-social, política, econômica e cultural pela qual passam as professoras, possibilitando, nesse contexto, processos de constituição identitária singulares, subjetivos e maleáveis que se consolidam na medida em que a pessoa/professor envereda os múltiplos espaços/tempos de vivências e experiências formadoras onde transita em seu percurso existencial. 


\section{Nesse sentido:}

[...] as identidades não são nunca unificadas; que elas são, na modernidade tardia, cada vez mais fragmentadas e fraturadas; que elas não são, nunca, singulares, mas multiplamente construídas ao longo de discursos, práticas e posições que podem se cruzar ou ser antagônicos. As identidades estão sujeitas a uma historicização radical, estando constantemente em processo de mudança e transformação (HALL, 2014, p. 108).

Portanto, em razão da multiplicidade de sujeitos com os quais estabelecemos relações, dos saberes aprendidos e compartilhados, dos contextos trilhados, das experiências e conhecimentos construídos, vamos nos moldando, influenciando o mundo e sendo por ele influenciado e afetado, permitindo outras possibilidades de constituições subjetivas que vão nos tornando o que somos ou estamos sendo, que não é mais o mesmo do passado, não estamos sendo no presente e nem o seremos no futuro, pois todo acontecimento vai nos atravessando por uma infinidade de mutações ao longo do tempo e do mundo que nos cerca.

Daí a ideia da temporalidade narrativa expressa em Ricoeur (2010), que situa o plano da ação na configuração da tessitura narrativa como uma experiência que somente o sujeito tem acesso quando as histórias são narradas, ou nas palavras do autor: "[...] uma vida humana é uma história em estado nascente" e somente ao narra-la "[...] temos acesso aos dramas temporais da existência" (RICOEUR, 2010, p. 127).

Ao longo do artigo, o uso do gênero feminino ao nos reportarmos ao termo "professoras" é por uma escolha política, por respeito às mulheres e por valorização às próprias professoras iniciantes pesquisadas que fizeram parte deste estudo, além de que a docência, em sua maioria, é constituída por mulheres.

Este texto dialoga com autores do campo da Pesquisa Narrativa (Auto)Biográfica e as Histórias de Vida, na perspectiva de Ricoeur (2010), Josso (2010), Candau (2012), DeloryMomberger (2008, 2014), Nóvoa (2010), Ca- tani e outros (2003), Bragança (2012), entre outros.

Trata-se de uma pesquisa de abordagem qualitativa, primando como dispositivos teórico-metodológicos as histórias de vida, por meio, especialmente, do diário de pesquisa e das narrativas orais, dispositivos estes que foram desenvolvidos na pesquisa-formação com as três professoras iniciantes que atuam nos anos iniciais do Ensino Fundamental, numa escola da rede pública de ensino de Caxias (MA).

A problemática de partida sobre a qual nos debruçamos é saber: Quais as implicações das histórias de vida de professoras iniciantes no processo de constituição da docência? E o que essas histórias de vidas narradas pelas docentes pode significar na escolha da profissão e no cotidiano da sua formação e do desenvolvimento profissional?

Os objetivos do artigo buscam: compreender as implicações das histórias de vida na constituição da docência de professoras em início de carreira, bem como refletir acerca das potencialidades das histórias de vida no desenvolvimento profissional de professoras iniciantes.

0 recorte cronológico do estudo compreende um contexto contemporâneo, por buscar dar visibilidade às histórias formativas do ser e fazer-se professora no século XXI, na constituição de suas identidades profissionais, mais especificamente, situadas no ano de 2014, período este em que foi realizada a pesquisa com as professoras iniciantes.

0 presente artigo também se inscreve como uma pesquisa-formação que vem nos acompanhando atualmente, tanto em relação à construção do texto de tese de doutorado em educação do primeiro autor, que está em curso no Programa de Pós-graduação em Educação da Universidade Estadual de Campinas (UNICAMP), orientado pela segunda autora deste escrito, como mediado pelas reflexões, discussões e estudos que estamos realizando nos grupos de pesquisa dos quais fazemos parte, a saber o Grupo de Pesquisa-Formação Polifonia, 
vinculado ao Grupo de Estudos e Pesquisas em Educação Continuada (GEPEC) da Faculdade de Educação da Unicamp e ao Núcleo Vozes da Educação da Faculdade de Formação de Professores da Universidade Estadual do Rio de Janeiro (FFP/UERJ).

Em relação à ideia de pesquisa-formação a qual aludimos acima, tem a ver com a proposição de Josso (2010) que tomamos emprestada, significando, portanto, processos de pesquisa que se inscrevem simultaneamente como formação e (auto)formação, ou seja, a pesquisaformação "é uma experiência a ser elaborada para que quem nela estiver empenhado possa participar de uma reflexão teórica sobre a formação e os processos por meio dos quais ela se dá a conhecer" (JOSSO, 2010, p. 142).

\section{A potência das histórias de vida como dispositivo metodológico de pesquisa-formação em educação}

As histórias de vida surgiram primeiramente como um modo de conversação e prática recorrente no âmbito da vida privada, entre famílias em que os pais, avós e parentes mais velhos passavam os ensinamentos, modos de vida, acontecimentos e fatos que tiveram no plano da experiência do passado em suas vidas, para as novas gerações, a fim de trocarem saberes e aprendizados de vários âmbitos da vida, da sociedade e da existência (BRAGANÇA, 2012).

No que diz respeito mais especificamente ao campo metodológico utilizado no âmbito científico, vale salientar que:

A incorporação das histórias de vida como caminho metodológico expõe, para as ciências humanas e sociais, o desafio de trabalhar fora do quadro lógico-formal e positivista, reenviando o olhar para uma perspectiva aberta à incorporação da subjetividade como elemento fundamental da constituição epistemológica do saber nesse campo do conhecimento, já que fundada na interação social, no olhar do sujeito. (BRAGANÇA, 2012, p. 38).
Nesse sentido, as histórias de vida têm se configurado como um pertinente dispositivo de acesso à interioridade do sujeito, a partir de suas reflexões tecidas narrativamente acerca do que viveu ou experienciou no passado, e que podem representar modos outros de acesso à história da constituição do ser pessoa e profissional em vários campos da profissão e do saber ao longo do tempo, mediado pelos entrelaçamentos e contextos por onde trilhou em seus itinerários formativos.

Buscando explorar a ideia de uma "pesquisa-formação" que aludimos neste texto, vale ressaltar que é um termo trabalhado por Josso (2010), e que para nós tem o significado da articulação e indissociabilidade entre os processos de pesquisa e de formação para o sujeito, uma vez que ambos se entrelaçam simultaneamente, em que o pesquisador vai aprendendo, escolhendo e construindo dispositivos metodológicos, modos de escrita, fontes e estilos de produzir o conhecimento, caracterizando-se, muitas vezes, como possibilidades de (auto) formação no decurso da vida.

Portanto, consideramos que a pesquisaformação trata de um processo de imersão do sujeito no contexto da pesquisa, impulsionando reflexões acerca dos percursos trilhados que vão se articulando com o plano da ação-reflexão-ação, do que sabe, conhece e mobiliza em razão do aprendido em múltiplos contextos que se apropria ao longo da vida, sobretudo da pesquisa e da formação que tece do vivido e experienciado.

Bragança (2018) também vem defendendo a pesquisa-formação como uma dimensão disparadora da constituição da experiência e transformação do sujeito no decurso dos contextos onde tece relações e aprendizagens, como recurso privilegiado que potencializa as narrativas e memórias destes, na perspectiva de uma tessitura de uma epistemologia outra que possa permitir a construção de outros tantos modos de viver, pesquisar e de se formar, o que a autora vai chamar de pesquisaformação narrativa (auto)biográfica. 
Por muito tempo a ciência trilhou o seu caminho baseando-se na perspectiva de uma concepção positivista e newtoniana-cartesiana de produzir conhecimento. Contudo, em decorrência das inúmeras mudanças que foram se operando na sociedade, chegou-se um momento em que não era possível mais dar conta das problemáticas vivenciadas em muitos contextos, sobretudo no âmbito da educação. 0 sujeito ficou por muito tempo invisibilizado, em detrimento de uma visão vertical e hierárquica, inviabilizando, portanto, um olhar holístico que pudesse concebê-lo em sua inteireza e a partir de sua subjetividade, como possibilidades mediadoras de gerar transformações plausíveis de si, e, consequentemente, na educação e na sociedade.

Numa perspectiva histórica, Delory-Momberger (2014), no livro As histórias de vida: da invenção de si ao projeto de formação, elucida que o gênero (auto)biográfico ganha seu teórico e historiador com Philippe Lejeune, que define suas características e situa sua emergência no século XVIII, por meio de "Confissões" de Rousseau, o qual evidencia o nascimento e texto fundador deste gênero. Enquanto nas Ciências Sociais as histórias de vida vão surgir, originalmente, por volta dos anos de 1920, na Escola de Chicago, nos Estados Unidos, e na Europa, o seu renascimento se dá pela contraposição aos modelos quantitativos da sociologia e a rejeição do sujeito pelo estruturalismo e marxismo, e, portanto, se iniciam então em 1970, com Daniel Bertaux, que foi seu iniciador na França, orientado para os campos profissionais com a abordagem biográfica, que desenvolveu trabalhos na sociologia crítica a partir das fontes de histórias de vidas dos sujeitos em trajetórias e percursos profissionais.

No que concerne ao desenvolvimento das histórias de vida como dispositivo heurístico de formação e como disparadora para (re)colocar o sujeito como protagonista de sua própria vida, de sua história, e com o qual entendemos e corroboramos neste texto, vale ressaltar que:
[...] 0 recurso da história de vida como prática de formação inscreve-se num contexto marcado pelos distúrbios socioprofissionais e familiares que afetam uma sociedade em plena transformação e pela perda das referências tradicionais que permitiram ao indivíduo construir-se um fio de etapas claramente reconhecidas, sucedendose segundo uma ordem imutável. A fratura das estruturas e a precariedade da vida profissional obrigam o indivíduo a operar um reajuste permanente de sua vivência e a proceder, para esse fim, a uma reapropriação constante do sentido de sua vida. A prática da história de vida, aparece, assim, como a forma de o sujeito, acedendo à sua própria historicidade, ser o ator da sua vida. (DELORY-MOMBERGER, 2014, p. 36-37, grifo do autor).

Do mesmo modo, entendemos que na história de vida o sujeito revela uma dimensão histórico-temporal de uma época, de um modo de ser, de se comportar e que envolve outras múltiplas dimensões sociais, culturais, profissionais e pessoais em razão do modelo de sociedade em que viveu ou experienciou, e que isso repercute em seu perfil e identidade que se apresentam na atualidade.

Ou como melhor clarificam Bolívar e outros (2001, p. 38, tradução nossa), “[...] cada modelo de relato de vida mostra uma perspectiva do 'eu', pegando - em diferentes porções - partes de uma realidade (pessoal, social, ideal, oculto, real) que, ao serem confrontadas dialeticamente, surge um novo 'eu reconstruído'”.

Assim, o surgimento das histórias de vida, como campo de pesquisa, formação e desenvolvimento profissional na educação, foi impulsionado pela ideia de "recolocar os professores no centro dos debates educativos e das problemáticas da investigação" (NÓVOA, 1992, p. 15). Nessa direção, na década de 1980 houve o que Nóvoa chama de "viragem paradigmática", dando lugar ao sujeito como pessoa e profissional, e assim a centralidade foi sendo dada mais ainda em suas narrativas, relatos e histórias de vida, contrapondo-se a um modelo de racionalidade técnica que fugia dos princípios de construção das identidades pessoais e profissionais, e, portanto, da democracia 
e da emancipação destes sujeitos, mediadas por processos mais amplos que poderiam ser gerados por reflexões e modos de se perceber no mundo e nos contextos onde poderiam ir se engajando, se transformando e transformando o meio à sua volta.

Nesse sentido,

No contexto da formação de professores, a abordagem das histórias de vida se coloca também no movimento de mudança paradigmática; um novo olhar sobre o/a professor/a e sua prática vai sendo tecido, indicando mudanças no campo da formação, da investigação e das práticas. (BRAGANÇA, 2012, p. 74).

As histórias de vida, portanto, buscam recuperar o sujeito em seu cotidiano, a partir da inteireza que o mesmo apresenta, sem fragmentar a vida, a profissão e a existência. Trata-se, pois, de dar visibilidade ao seu desenvolvimento numa perspectiva micro, pelo que faz e pelo que pensa, mobiliza, sente, e que tudo isso, e suas narrativas historiadas sobre esse processo, traz implicações na constituição de sua história, da sua pessoa e da sua profissão, para então compreendermos como se dá a estrutura das relações sociais, intersubjetivas e no plano da subjetividade, bem como das transformações da profissão, entre outras questões numa dimensão macro.

A potência das histórias de vida se reverbera a partir do momento em que o sujeito se vê implicado em um contexto, narra todos esses processos vivenciados, experienciados e que lhe tocam numa dimensão de implicação, de atravessamento, o que o faz ir refletindo com e acerca de suas ações, de como se vê, e do que poderá melhorar em seu percurso existencial e profissional, gerando, portanto, possibilidades de transformações e emancipação, pela tomada de consciência que faz ao ler o que narrou de sua história que viveu ou experienciou em algum momento de sua existência.

Cabe, portanto, dar legitimidade no âmbito da pesquisa-formação com as histórias de vida na educação, tendo em vista que "[...] Ao serem trabalhados, esses relatos favorecem o redi- mensionamento das experiências de formação e das trajetórias profissionais e tendem a fazer com que se infiltrem na prática atual novas opções, novas buscas e novos modos de conduzir o ensino" (CATANI et al., 2003, p. 19).

Em relação ao modo como são organizadas as histórias de vidas das professoras iniciantes pesquisadas, e como forma de respeitar os aspectos éticos e legais da pesquisa científica, não iremos revelar os nomes das mesmas, sendo resguardadas suas identidades. Primamos, portanto, pelo uso apenas das letras iniciais dos seus dois primeiros nomes.

As histórias de vida das professoras participantes da pesquisa foram produzidas no cotidiano da escola, na relação entre pesquisadores e professoras, por meio da gravação em aparelho de áudio e depois transcritas para o computador, somando-se às observações e aos registros do diário de pesquisa; depois foi feito um entrelaçamento entre esses dispositivos metodológicos, em que fomos questionando e conversando com elas, sobre como se tornaram professoras e como chegaram até onde chegaram e estão atualmente, permitindo a construção do conhecimento e a produção deste artigo.

Quando ao fato de publicizar suas histórias de vida narradas, todas as professoras iniciantes que participaram do estudo assinaram um termo de autorização e concordaram com a publicação de suas falas nos meios de divulgação científica, e as mesmas foram informadas e esclarecidas dos respectivos procedimentos e alcances que a publicação poderia ter.

Nesse sentido, durante nossas conversas as professoras acessaram suas memórias e histórias, conforme iam se lembrando do que fizeram no passado e dos contatos que tiveram enquanto estavam exercendo determinadas práticas e atividades que tinham a ver com a educação, e em alguns casos na própria escola e na sala de aula, e que mobilizaram determinados saberes e fazeres, mesmo sem saberem o suficiente como fazê-lo, do que tinham a ver com a educação, para então "dar conta" do reca- 
do, por aprendizado ou curiosidade, conforme será elucidado nas suas histórias de vida.

\section{Histórias de vida de professoras iniciantes: memórias do passado fazendo-se no presente}

Nesta seção são apresentadas as histórias de vidas das três professoras iniciantes participantes da pesquisa. Assim, é feito um entrelaçamento entre três dimensões da pesquisa científica: metodologia, empiria e teoria. Tais dimensões vão para além dos próprios relatos narrativos evidenciados das docentes, de modo a acessar níveis de reflexão e compreensão acerca da escolha profissional da docência como profissão, a partir do passado que vivenciaram e tiveram experiências de alguma forma com a área da educação, constituindo, portanto, suas identidades profissionais no tempo da história presente, ou seja, no momento contemporâneo em que estão vivendo e experienciando a profissão.

As três professoras iniciantes participantes começaram sua profissão como docentes na escola em que estavam atuando no momento da realização da pesquisa; duas delas, A.C. e O.L., junto com o início das atividades da escola, ainda no processo de surgimento da instituição. Quanto à professora I.R., entrou na escola em seu segundo ano de existência, no lugar de outra professora, que teve que se afastar para licença-maternidade, não retornando mais para a escola, e, portanto, I.R. acabou assumindo e permanecendo no lugar da outra professora, ficando até o momento em que ocorreu a pesquisa como docente da instituição.

Todas as três professoras iniciantes trabalhavam, antes de serem professoras, em outras áreas completamente diferentes da educação. Exerciam atividades no comércio ou em cargos públicos do município. E no período em que foi realizada a pesquisa, identificamos que as professoras iniciantes estavam atuando na escola no regime de contratos temporários, sujeitos a renovação a cada ano letivo na rede municipal de ensino, e não possuíam outros empregos, nem trabalhavam em turnos dobrados na escola. $\mathrm{O}$ que as mobilizou, sempre com muita preocupação, a aprenderem "novos" saberes e fazeres que pudessem ser desenvolvidos em sua prática pedagógica, já que precisavam mostrar trabalho para permanecerem no cargo de professoras na escola.

Três eixos ou dimensões formadoras perpassam todas as narrativas das professoras iniciantes, os quais conseguimos depreender de suas histórias de vida, quais sejam: memória, identidade e desenvolvimento socioprofissional.

Diante do exposto, entendemos que o entrelaçamento entre as dimensões da memória, identidade e desenvolvimento profissional docente se faz presente constantemente nas histórias de vidas das professoras iniciantes pesquisadas. Assim, "[...] a narrativa de vida individual e coletiva faz parte da forma propriamente humana de construir/recriar conhecimentos, de preservar a memória, de criar as identidades, de atribuir a objetos e lugares valor simbólico" (BRAGANÇA, 2012, p. 41).

Algumas das narrativas de suas histórias de vida foram reveladas em conversas que tivemos entre pesquisadores e participantes, em que as professoras, tanto de modo individual, com apenas uma delas, como coletivamente, entre pesquisadores e mais duas professoras, foram dizendo em alguns espaços da escola em que atuam (em sala de aula, na sala dos professores ou outros espaços em momentos em que somente nós estivéssemos dialogando) o que faziam pelo que aprenderam no passado quando tiveram alguma experiência, seja no âmbito familiar com seus filhos, como com suas mães, tias ou outros(as) conhecidos e parentes que trabalhavam na educação, foram professoras ou tiveram algum contato com processos didáticos, pedagógicos e de construção de dispositivos metodológicos e materiais concretos no cotidiano de sua formação e desenvolvimento profissional, ou em casa, quando estavam 
em momentos de planejamento da prática pedagógica.

Como as histórias de vida evocadas pelas professoras iniciantes pesquisadas revelam muito de suas escolhas profissionais, um estudo acerca disso evidenciou que:

0 fato de uma escolha profissional, traz consequências e contribuições no cotidiano profissional. E isso pode significar perdas ou ganhos, em relação ao desenvolvimento da competência profissional, sobretudo, no modo como realizamos o nosso trabalho e lidamos com as pessoas que participam ou entram em contato diretamente com nosso saber/fazer cotidianos. (MORAIS, 2017, p. 413).

Apresentamos a seguir o perfil de cada uma das professoras iniciantes, seguido de suas histórias de vida, que foram narradas à medida que foi sendo realizada a pesquisa, e que estavam relacionadas com a sua prática pedagógica cotidiana exercida na escola pública nos anos iniciais do $1^{\circ}$ ao $5^{\circ}$ ano do Ensino Fundamental, na realidade pesquisada.

A professora A.C. tem 33 anos. Possui formação em Magistério, em 1999, graduação em Pedagogia, em 2012, especialização em Supervisão e Gestão Escolar, em 2013, além de curso em Libras, em 2013. Realizou toda a escolarização na rede pública de ensino. Segundo evidencia em sua narrativa, acerca da constituição da docência como profissão, nos informou que:

[...] sempre gostei da profissão; minha mãe é professora e minhas tias também, e sempre que podia as ajudava nas atividades, trabalhos e nas questões relacionadas às suas práticas pedagógicas. Quando fiz o ensino médio, já me identificava com a educação, ampliando esse gostar com a realização do curso de magistério, passando a criar cada vez mais gosto e prazer, buscando me aprofundar, aprimorar e melhorar os saberes relacionadas às práticas educativas. Não me vejo em outra área a não ser como professora mesmo, pois gosto do que faço. Passei a ser professora da escola que atuo até hoje, por convite de pessoas que conheciam o meu trabalho e permaneço atualmente como docente da instituição. (A.C., 2014).
Diante do exposto, podemos refletir que os momentos em que teve contato na situação de processos de aprender e ensinar foram vivenciados e experienciados pela professora A.C. com fazeres e saberes que ia construindo de forma didática e metodologicamente, conforme narra, mesmo que acontecesse de modo inconsciente, sem focar especificamente o ensinar, pois ela apenas ajudava suas tias e sua mãe nos afazeres relacionados à construção dos materiais e atividades que iam desenvolver em sua prática. Do mesmo modo, é possível refletir que o fato de dizer que escolheu a docência como vida e profissão tem a ver com os acontecimentos a que se lançou no passado, e que marcaram sua história de vida, e isso vai rememorando cada vez que se lembra como iniciou a profissão docente.

Vemos ainda que as práticas em que vamos nos lançando no plano da experiência enquanto fazer vão despertando determinados gostares ou não, dependendo do que é feito, para qual função e em razão de algum determinado contexto. No caso da professora A.C., podese perceber que ela foi conquistada pelo que fazia, ou seja, acabou lhe trazendo sensações, representações e significações positivas, o que pode ter influenciado, inclusive, na escolha de sua profissão de professora.

Diante da história de vida da professora A.C. enunciada acima, entendemos que se faz presente a ideia de três tempos da narração, que seria uma "tríplice equivalência", conforme esclarece Paul Ricoeur (2010) em Tempo e Narrativa ao pensar nos estudos que fez sobre as "Confissões" de Santo Agostinho, de que existe um presente do passado, um presente do presente e um presente do futuro. Assim, o presente do passado é a memória, o presente do presente é a visão, e o presente do futuro é a expectativa.

Clarificando pormenorizadamente como se dá essa tríplice equivalência no âmbito da temporalidade narrativa a que alude Ricoeur (2010), poderíamos pensar que o presente do passado estaria onde a professora narra 
que: “[...] sempre gostei da profissão, minha mãe é professora e minhas tias também, e sempre que podia as ajudava nas atividades, trabalhos e nas questões relacionadas às suas práticas pedagógicas". Quanto ao presente do presente, poderíamos pensar quando evidencia que: "Passei a ser professora da escola que atuo até hoje, por convite de pessoas que conheciam o meu trabalho e permaneço atualmente como docente da instituição". E em relação ao presente do futuro, está onde a professora diz: "Não me vejo em outra área a não ser como professora mesmo, pois gosto do que faço."

É com base nas ideias do antropólogo Jöel Candau (2012) acerca de uma reflexão entre memória e identidade como dimensão constitutiva do ser em relação com o que narra de acontecimentos, do que vivencia e experiencia em seu cotidiano, que é possível articular com os múltiplos contextos os quais se engajam social e culturalmente as professoras iniciantes. $\mathrm{E}$ no caso da professora A.C. podemos relacionar que "Através da memória o indivíduo capta e compreende continuamente o mundo, manifesta suas intenções a esse respeito, estrutura-o e coloca-o em ordem (tanto no tempo como no espaço) conferindo-lhe sentido" (CANDAU, 2012, p. 61).

É, pois, uma forma de dá sentido à existência e à profissão, que vai, inclusive, desbravando outras memórias do passado, narrando-as no presente, o que Josso (2010, p. 37), vai chamar de "recordações-referência”, que "[...] significa, ao mesmo tempo, uma dimensão concreta ou visível, que apela para nossas percepções ou para as imagens sociais, e uma dimensão invisível, que apela para emoções, sentimentos, sentido ou valores".

Já em relação à professora I.R., tem 24 anos, possui graduação em Pedagogia, em 2012, especialização em Supervisão, gestão e planejamento educacional, em 2014. Cursou toda a escolarização também na rede pública de ensino e disse que não sofreu nenhuma dificuldade quando estudava no ensino básico. Assim se posicionou a professora I.R. em relação à escolha da profissão de professora:

Quanto à escolha da profissão de professora não se deu por influências familiares, mas por escolha pessoal mesmo. Iniciei minhas atividades como professora na escola que me encontro até hoje, por intermédio de convites, já que tinha concluído o curso de Pedagogia e não estava atuando na área da educação, portanto, resolvi exercer a docência pelo fato de estar precisando trabalhar, e também por ter formação na área. (I.R., 2014).

Nesse sentido, ao narrar sobre si, a partir do que entende, compreende, reflete e como toma as experiências e vivências como acontecimentos trilhados no percurso existencial, o sujeito vai dando forma às suas histórias de vida, que vai diferenciando-se de um espaço/ tempo para outro, bem como dos aspectos que vão trazendo implicações durante a sua história do ser e fazer-se professora e de todos os atravessamentos que permitiram dizer o que diz no momento em que evoca a sua narrativa, fruto de sua história de vida. Essa dimensão reflexiva pode ser corroborada com a ideia de que "[...] a narração é o lugar no qual o indivíduo toma forma, no qual ele elabora e experimenta a história de sua vida" (DELORY-MOMBERGER, 2008, p. 56).

Por outro lado, cabe refletir que as exigências que a sociedade neoliberal, no contexto contemporâneo, vai colocando de modo hegemônico e partindo de uma supremacia, preconizada pela onda avassaladora do consumismo, forjado pelo capitalismo, cada sujeito vai respondendo a modos diferentes de se perceber e de tecer os seus caminhos pessoais e profissionais, em decorrência do que acontece e como toma o acontecimento para si. Trata-se, pois, de uma ideia suscitada pela "sociedade do hiperconsumo", expressão batizada pelo filósofo francês Gilles Lipovetsky (2015), e que tem a ver com as necessidades criadas pela era da globalização, que condicionam os sujeitos a "[...] viver melhor, 'gozar a vida', a usufruir do conforto e das novidades comercializadas" (LIPOVETSKY, 2015, p. 86-87). 
O fato de trabalhar, portanto, é uma forma de subsistência que nos lança ao usufruto dos dispositivos materiais e pessoais que possamos conquistar, e que criam "fluxos de desejos" que acabam nos tornando reféns e nos enquadrando na lógica do capital para obtermos o que queremos e desejamos, como uma questão de satisfação.

No caso da professora I.R., nota-se que sua narrativa de escolha da profissão tem um viés bem forte, amparado nessa perspectiva ao reforçar que escolheu ser professora "pelo fato de estar precisando trabalhar".

Por isso, a ideia de "hiperconsumidor" a que faz alusão Gilles Lipovetsky (2015) em A felicidade paradoxal acaba, muitas vezes, criando inconscientemente uma ideia, gostos e preferências para usufruir dos bens de consumo que boa parte da sociedade midiática, outros meios ideológicos e de comunicação fazem-no acreditar como uma necessidade premente. E o emprego, ou o fato de trabalhar, gera essa sensação ou representação de adquirir ou conquistar o que não se tem ainda, ou que poderá ter.

Reforçamos que a escolha da profissão docente se reverbera na concepção que se tem, bem como das influências que se teve e do que é desejado no plano pessoal e social pelo sujeito. Daí a importância de compreendermos as histórias de vida das professoras iniciantes participantes da pesquisa, porque muito do que narram tem implicações das mais diferentes formas no que entendem e fazem no cotidiano de sua prática pedagógica.

No que se refere à professora O.L., possui 26 anos, tem formação em Magistério em nível Normal, em 2010, e encontrava-se cursando Pedagogia no período em que foi realizada a pesquisa (no 7o período do curso) numa faculdade privada. Morou em zona rural, onde iniciou seus estudos no Ensino Fundamental, não cursando Educação Infantil por não existir na época e no local onde morava. Seu processo de alfabetização se deu através de sua mãe, que era professora, e que também lhe ensinava na escola. Cursou toda a escolarização na rede pública de ensino, chegando a ir para a cidade para continuar seus estudos por necessitar de uma melhor aprendizagem já no ensino médio. A professora O.L. pontuou em sua fala que:

[...] cheguei a assumir o trabalho na sala de aula quando minha mãe se ausentava para resolver algumas situações para o sustento da família, e então ficava desenvolvendo atividades e práticas pedagógicas no processo de alfabetização, de acordo com o que tinha observado das experiências da minha mãe como educadora. Eu fazia isso sem ter formação ainda, somente enquanto minha mãe concluía determinadas obrigações familiares. Quanto à escolha da profissão de professora, não tinha menor interesse, e sim gostava da área de Agronomia e Fisioterapia. Cheguei até a passar no vestibular para Agronomia numa instituição em outra cidade distante da que eu morava, mas por não ter condições econômicas para cursar, desisti. Ingressei no curso de magistério por opção, e mesmo sem saber e conhecer muito bem, fui criando gosto e prazer pela educação, passei a tomar a decisão, de fato, para ser educadora sem pensar em outra profissão. No 5o período do curso de Pedagogia, surgiu a oportunidade de eu trabalhar na EJA [Educação de Jovens e Adultos], e cheguei a levar toda a documentação para assumir a vaga, mas desisti, e então encontrei no mesmo período uma escola que estava precisando de professores, então entreguei o meu currículo e fui posteriormente contratada. É a escola que permaneço até hoje como docente. (O.L., 2014).

0 potencial de implicação da história de vida da professora O.L. reside no fato de que ela própria foi aos poucos construindo a sua formação com base num balanço de vida (perspectiva retrospectiva), conforme faz alusão Nóvoa (2010). Nesse sentido, ainda para esse autor, é nesse momento que é possível situar o conceito de "reflexividade crítica", fruto do entrelaçamento entre as dimensões anteriores, que resultaria nesse processo de refletir sobre si e sua formação, gerando, então, transformações relevantes na vida e na profissão.

É possível ainda depreender, com base em sua história de vida narrada, que a professora O.L. passou por inúmeros contextos e atraves- 
samentos, constituindo múltiplas identidades que foram sendo tecidas em razão do que aconteceu em sua vida cotidiana, com os sujeitos com os quais estabeleceu relações e das escolhas que fez em detrimento de outras. Isso tem muito com o que elucida Hall (2014, p. 109):

É precisamente porque as identidades são construídas dentro e não fora do discurso que nós precisamos compreendê-las como produzidas em locais históricos e institucionais específicos, no interior de formações e práticas discursivas específicas, por estratégias e iniciativas específicas.

Do mesmo modo, as experiências formadoras que a professora O.L. tivera no passado, e acessadas no plano da memória, permitiram à professora iniciante (re)elaborar os saberes da prática pedagógica, com base no contexto e realidade que se apresentava, no momento em que estava se defrontando profissionalmente. Fato este que foi consubstanciado pelas nossas observações no cotidiano de sua prática, e que foi, inclusive, caracterizado por processos de criação e (re)criação de saberes, materiais pedagógicos e atividades outras extrapolando o currículo oficial, utilizando suas "astúcias" de "táticas" e "estratégias" ao mesmo tempo, diante das práticas instituídas hegemonicamente (CERTEAU, 2012).

Cabe, portanto, pensar reflexivamente, diante do exposto, que

Ao lançar um olhar mais detido e mais arguto sobre seu passado, os professores têm a oportunidade de refazer seus próprios percursos, e a análise dos mesmos tem uma série de desdobramentos que se revelam férteis para a instauração de práticas de formação (CATANI et al., 2003, p. 32).

Do mesmo modo, com base na história de vida narrada pela professora O.L., compreendemos com Ricoeur (2010, p. 116) que “[...] entender a história é entender como e por que os sucessivos episódios conduziram a essa conclusão, que, longe de ser previsível, deve ser finalmente aceitável, como sendo congruente com os episódios reunidos".
Podemos ainda depreender que a narração das histórias de vidas das professoras iniciantes se faz presente em diferentes acontecimentos que situam as marcas de vivências e experiências com o contato em processos de aprender e ensinar a serem professoras, e que se configurou com diferentes implicações, intensidades e características em suas vidas, e que é retratado com as reminiscências das memórias com as quais conseguem se lembrar. Desse modo, entendemos, como Ricoeur (2010), que nas histórias narradas se faz presente ao mesmo tempo memória e expectativa com o ser professora, com o que poderá encontrar na sua profissão e com a própria permanência e sobrevivência na profissão de professora. Ou seja, “[...] narração, diremos, implica memória, e previsão implica expectativa. Porém, o que é lembrar-se? É ter uma imagem do passado. Como isso é possível? Porque essa imagem é um vestígio deixado pelos acontecimentos que permanece fixado na mente" (RICOEUR, 2010, p. 22).

Portanto, as histórias de vida representam um recurso privilegiado para captar tanto as escolhas da profissão de professora, como das concepções e modos de organização do trabalho pedagógico, e dos aspectos de uma época e tempo histórico, social, político e cultural os quais viveram em algum momento de suas vidas formativas.

\section{Uma breve sintese...}

A pesquisa nos permitiu inferir que as histórias de vida têm um potencial transformador na vida do sujeito que narra sua história, pois permitem acessar acontecimentos do passado que foram marcantes em sua vida, fazendo repensar o contexto atual, suas práticas e processos formativos.

Em se tratando das professoras iniciantes, as que participaram da pesquisa percebem que suas experiências e vivências tidas no passado fizeram perceber no momento atual em que narraram suas histórias de vida, que foram relevantes e disparadoras para a escolha da 
docência como vida e profissão, e o contato que tiveram e fizeram com alguns fazeres e saberes relacionados à educação fizeram-nas aprender e (re)elaborar suas formas de desenvolver o trabalho pedagógico, porque foram aperfeiçoando, ao longo do tempo, o olhar e as práticas metodológicas com as quais iam desenvolvendo, já em outro momento de suas vidas, como aprendentes de professoras, assumindo a responsabilidade sozinhas de uma turma com vários alunos de diferentes perfis, identidades, subjetividades e heterogeneidades.

As histórias de vida, portanto, revelam inúmeras possibilidade de pensar a profissão docente, e os modos como vai se configurando o ser professor no contexto da sociedade contemporânea, evidenciando, ainda, perfis identitários de ser professora iniciante, que se diferenciam de outros tempos/espaços e momentos históricos da profissão docente. Suas potencialidades são vistas, em suma, como transformadoras e emancipadoras, a partir do momento em que a professora iniciante olha o seu passado e consegue se ver diante de uma nova realidade que não é mais a mesma, e que, por isso mesmo, acaba ressignificando o que é ou está sendo, bem como o que está mobilizando de saberes e fazeres, que gera transformações plausíveis em sua vida e profissão, e que só é possível captar essa dimensão quando narra suas histórias de vida, apresentando um teor de reflexividade constituída de novas ideias, concepções e modos de ser e estar na profissão como professora iniciante na sociedade atualmente.

As histórias de vidas, portanto, como dispositivo de pesquisa-formação, dão legitimidade à tessitura de saberes, conhecimentos e experiências potentes que contribuem para modos outros de ser professora, mediatizados por processos reflexivos que resgatam, nas memórias e experiências do passado, elementos de referência que permitiram contribuir no ser pessoa e profissional que está sendo, bem como na escolha da profissão e nos modos como pensa e faz a sua prática pedagógica no contexto de sua imersão profissional.
Sendo assim, a tomada de consciência pelo que as histórias de vida permitem se inscrever na vida e profissão docente das professoras iniciantes significou não apenas um modo de rever como escolheram ser professoras, mas (re)pensar o passado, narrando-o no presente, e ao mesmo tempo pensando no futuro, o que tem muito a ver com a ideia de "composição da intriga", que Ricoeur (2010, p. 74) explicita, referindo-se, portanto, ao fato de que "compor a intriga já é fazer surgir o inteligível do acidental, o universal do singular, o necessário ou o verossímil do episódico", o que conseguimos perceber pelas histórias de vida com que teceram as professoras iniciantes, permitindo a elas a tessitura de uma inteligibilidade pelo narrado, que as fizeram refletir acerca do que foram e do que estão sendo no mundo atual como professoras iniciantes.

\section{REFERÊNCIAS}

BRAGANÇA, Inês Ferreira de Souza. Histórias de vida e formação de professores: diálogos entre Brasil e Portugal. Rio de Janeiro: EdUERJ, 2012. Disponível em: https://doi.org/10.7476/9788575114698. Acesso em: 07 nov. 2019.

BRAGANÇA, Inês Ferreira de Souza. Pesquisaformação narrativa (auto)biográfica: trajetórias e tessituras teórico-metodológicas. In: ABRAHÃO, M. H. M. B.; CUNHA, J. L. da; BÔAS, L. V. (org.). Pesquisa narrativa (auto)biográfica: diálogos epistêmico-metodológicos. Curitiba: CRV, 2018. p. 65-81.

BOLÍVAR, António et al. Lá investigación biográfico-narrativa em educación: enfoque y metodologia. Madri: Editorial La Muralla, 2001.

CANDAU, Joël. Memória e identidade. Tradução Maria Letícia Ferreira. 1. ed. 1. reimp. São Paulo: Contexto, 2012.

CATANI, Denise Bárbara et al. História, memória e autobiografia na pesquisa educacional e na formação. In: CATANI, D. B. et al (org.). Docência, memória e gênero: estudos sobre formação. 4. ed. São Paulo: Escrituras, 2003. p. 15-48.

CERTEAU, Michel de. A invenção do cotidiano: 1. artes de fazer. 19. ed. Tradução de Ephraim Ferreira Alves. Petrópolis, RJ: Vozes, 2012. 
DELORY-MOMBERGER, Christine. Biografia e educação: figuras do indivíduo-projeto. Tradução de Maria da Conceição Passeggi, João Gomes da Silva Neto, Luis Passeggi. São Paulo: Paulus, 2008.

DELORY-MOMBERGER, Christine. As histórias de vida: da invenção de si ao projeto de formação. Porto Alegre: EDIPUCRS, 2014.

HALL, Stuart. Quem precisa de identidade? In: SILVA, T. T. da (org.). Identidade e diferença: a perspectiva dos estudos culturais. 15. ed. Petrópolis, RJ: Vozes, 2014. p. 103-133.

JOSSO, Marie-Christine. Experiências de vida e formação. Tradução de José Cláudio, Júlia Ferreira; revisão Maria da Conceição Passeggi, Marie-Christine Josso. 2. ed. rev. e ampl. São Paulo: Paulus, 2010.

LIPOVETSKY, Gilles. A felicidade paradoxal: ensaio sobre a sociedade do hiperconsumo. 2 . reimp. Lisboa: Edições 70, 2015.
MORAIS, Joelson de Sousa. As histórias formativas de professoras iniciantes e suas implicações no processo de profissionalização. In: Anais do I encontro de História da Educação do MeioNorte do Brasil: educação comparada na história da educação. 1. ed. Timon, MA: EDIFMA, 2017. p. 411-425.

NÓVOA, António. A formação tem que passar por aqui: as histórias de vida projeto Prosalus. In: NÓVOA, A.; FINGER, M. (org.). 0 método (auto) biográfico e a formação. São Paulo: Paulus, 2010. p. 155-187.

NÓVOA, António. Os professores e as histórias da sua vida. In: NÓVOA, A. (org.). Vidas de professores. Porto: Porto editora, 1992. p. 11-30.

RICOEUR, Paul. Tempo e narrativa. Vol. 1. Tradução Claudia Berliner; Revisão da tradução: Márcia Valéria Martinez de Aguiar. São Paulo: Martins Fontes, 2010.

Recebido em: 07/11/2019

Aprovado em: 20/02/2020 